\title{
Correlation between carboxylesterase alleles and insecticide resistance in Culex pipiens complex from China
}

Yangyang Liu', Hanying Zhang ${ }^{2}$, Chuanling Qiao ${ }^{2}$, Xiping $\mathrm{Lu}^{1 *}$ and Feng Cui ${ }^{2^{*}}$

\begin{abstract}
Background: In China, large amounts of chemical insecticides are applied in fields or indoors every year, directly or indirectly bringing selection pressure on vector mosquitoes. Culex pipiens complex has evolved to be resistant to all types of chemical insecticides, especially organophosphates, through carboxylesterases. Six resistant carboxylesterase alleles (Ester) were recorded previously and sometimes co-existed in one field population, representing a complex situation for the evolution of Ester genes.

Results: In order to explore the evolutionary scenario, we analyzed the data from an historical record in 2003 and a recent investigation on five Culex pipiens pallens populations sampled from north China in 2010. Insecticide bioassays showed that these five populations had high resistance to pyrethroids, medium resistance to organophosphates, and low resistance to carbamates. Six types of Ester alleles, Ester ${ }^{B 1}, E_{s t e r}{ }^{2}, E_{s t e r}^{8}, E_{s t e r}{ }^{9}, E_{t e r}{ }^{B 10}$, and ster $^{11}$ were identified, and the overall pattern of their frequencies in geographic distribution was consistent with the report seven years prior to this study. Statistical correlation analysis indicated that Ester ${ }^{8}$ and Ester ${ }^{9}$ positively correlated with resistance to four insecticides, and $E s t e{ }^{B 10}$ to one insecticide. The occurrences of these three alleles were positively correlated, while the occurrence of Ester ${ }^{B 1}$ was negatively correlated with Ester ${ }^{8}$, indicating an allelic competition.

Conclusion: Our analysis suggests that one insecticide can select multiple Ester alleles and one Ester allele can work on multiple insecticides. The evolutionary scenario of carboxylesterases under insecticide selection is possibly "one to many".
\end{abstract}

Keywords: insecticide resistance, carboxylesterases, mosquito, evolution

\section{Background}

Mosquitoes, due to their special behavior, physiology and close relationship with humans, act as ideal transmitters of a wide variety of human disease agents, including filariasis, Japanese encephalitis, West Nile virus, dengue and malaria [1]. Chemical insecticides have been extensively used since the 1940 s to control mosquito vectors, and four major categories of insecticides have been sequentially applied historically: organochlorines, organophosphates, carbamates and

\footnotetext{
* Correspondence: Ixp59@sdau.edu.cn; cuif@ioz.ac.cn

'Plant Protection College, Shandong Agricultural University, Tai'an, Shandong, 271018 China

${ }^{2}$ State Key Laboratory of Integrated Management of Pest Insects \& Rodents, Institute of Zoology, Chinese Academy of Sciences, Beijing, 100101 China Full list of author information is available at the end of the article
}

pyrethroids [2-4]. In China, insecticide production is over $3.9 \times 10^{8} \mathrm{~kg}$ and application is around $2.5 \times 10^{8} \mathrm{~kg}$ annually since 1997; directly or indirectly bringing heavy selection pressure on mosquitoes [5]. As one of seven major species of vector mosquitoes in China, the Culex pipiens complex has evolved to be resistant to all types of chemical insecticides, except carbamates, in many regions [5].

Three gene families of detoxification enzymes are involved in metabolic resistance to chemical insecticides: carboxylesterases, P450 monooxygenases, and glutathione S-transferases [6]. Carboxylesterases often mediate resistance to organophosphates, carbamates, and to a lesser extent, pyrethroids [1]. In mosquitoes, non-specific carboxylesterases sequester, rather than rapidly

C Biomed Central

( 2011 Liu et al; licensee BioMed Central Ltd. This is an Open Access article distributed under the terms of the Creative Commons Attribution License (http://creativecommons.org/licenses/by/2.0), which permits unrestricted use, distribution, and reproduction in any medium, provided the original work is properly cited. 
metabolize, the pesticide molecules [7]. Two gene loci, Est-2 and Est-3, encode non-specific esterases through gene amplification or up-regulation in the $C$. pipiens complex $[8,9]$. These loci are always in complete linkage disequilibrium and referred to as the Ester superlocus. To date, twelve Ester alleles conferring OP resistance have been identified at the Ester locus (the corresponding overproduced esterases are named in parentheses): Ester $^{1}$ (A1), Ester ${ }^{2}$ (A2-B2), Ester ${ }^{4}$ (A4-B4), Ester ${ }^{5}$ (A5B5), Ester ${ }^{8}$ (A8-B8), Ester ${ }^{9}$ (A9-B9), Ester ${ }^{11}$ (A11-B11), Ester $^{B 1}$ (B1), Ester ${ }^{B 6}$ (B6), Ester ${ }^{B 7}$ (B7), Ester ${ }^{B 10}$ (B10) and Ester ${ }^{B 12}$ (B12) [5,9-11].

An unusual diversity of Ester alleles was observed in field populations from China, where Ester ${ }^{B 1}$, Ester ${ }^{2}$, Ester $^{B 6}$, Ester $^{B 7}$, Ester $^{8}$, Ester $^{9}$, Ester $^{B 10}$ and Ester ${ }^{11}$ were reported, and as many as six Ester alleles co-existed in one population [12]. This situation is atypical, and may represent a complex situation for the evolution of insecticide resistance genes in China. Accumulation and analysis of monitoring data will be helpful to understand the evolution of insecticide resistance genes in field mosquito populations.

In recent years, we monitored the resistance levels and Ester phenotype frequencies of $C$. pipiens complex field populations to organophosphates, carbamates, and pyrethroids at either the large scale or locally in China [13]. In order to explore the evolutionary scenario of Ester resistance alleles, we analyzed the data from five Culex pipiens pallens populations sampled in north China, and from an historical record from 2003 [12]. We investigated the resistance levels of these five populations towards three organophosphate, two pyrethroid, and two carbamate insecticides. Esterase phenotype frequencies of Ester locus were also quantified. Lastly, we combined our data with that of a large scale investigation from 2003 [12], and statistically analyzed the relationship between resistance level and Ester phenotype frequency for each insecticide, and among phenotype frequencies of various Ester alleles.

\section{Methods}

\section{Mosquito samples and strains}

Five field populations of C. p. pallens were collected as egg-rafts, larvae, or pupae in north China from July to August of 2010 (Table 1). They were raised for several generations in the laboratory at $25 \pm 1^{\circ}$ and a photoperiod of $14 \mathrm{~L}: 10 \mathrm{D}$. Several standard strains were used as references in bioassays or starch gel electrophoresis: S$\mathrm{LAB}$, an insecticide-susceptible strain without any known resistance genes [14]; SB1 strain, homozygous for Ester $^{B 1}$, displaying overproduced esterase B1; SA2 strain, homozygous for Ester $^{2}$, displaying overproduced esterases A2-B2 [15]; MAO2 strain, homozygous for Ester $^{8}$, displaying overproduced esterases A8-B8 [16]; LING strain, homozygous for Ester ${ }^{9}$, displaying overproduced esterases A9-B9 [16]; KARA2 strain, homozygous for Ester $^{B 10}$, displaying overproduced esterase B10 [5]; and WU strain, homozygous for Ester ${ }^{11}$, displaying overproduced esterases A11-B11 [5].

\section{Insecticide bioassays}

Resistance characteristics of larvae were determined by bioassays on fourth-instar larvae, following the methods described in Raymond and Marquine (1994) [17]. The test insecticides were three organophosphates, dichlorvos, fenitrothion, malathion, two pyrethroids, deltamethrin, permethrin, and two carbamates, propoxur, BPMC (2-sec-Butylphenyl methyl carbamate). Four or five doses and four replicates (20 larvae per replicate) per dose were performed with each insecticide. The mortalities of larvae were recorded after 24 hours of treatment. Larvae from S-LAB strain were tested at the same time as susceptible controls. Based on Finney (1971) [18] data were analyzed by the log-probit program of Raymond (1993) [19], which provides LCs, slope for each mortality line, parallelism between different mortality lines and resistance ratios with 95\% confidence intervals.

\section{Starch gel electrophoresis}

Ester allele phenotypes of individual adult mosquitoes were revealed using starch gel electrophoresis (TME 7.4 buffer system) as described by Pasteur et al. (1981; 1988) [20,21]. Mosquitoes from six standard strains (SB1, SA2, MAO2, LING, KARA2 and WU) were used as markers in electrophoresis to indicate the esterase phenotypes of field collected mosquitoes.

\section{Statistical analysis of correlation}

The data of 5 populations from this study and 20 populations from the investigation in 2003 [12] were

Table 1 Collection information of Culex pipiens pallens sampled in China.

\begin{tabular}{llll}
\hline Province & Locality (latitude, longitude) & Code & Date \\
\hline Henan & Weihe $\left(35^{\circ} 02^{\prime} \mathrm{N}, 113^{\circ} 8^{\prime} \mathrm{E}\right)$ & WHE & $15 / 07 / 2010$ \\
& Yuanyang $\left(35^{\circ} 02^{\prime} \mathrm{N}, 113^{\circ} 58^{\prime} \mathrm{E}\right)$ & YUY & $14 / 07 / 2010$ \\
Shandong & Taian $\left(35^{\circ} 38^{\prime} \mathrm{N}, 116^{\circ} 2^{\prime} \mathrm{E}\right)$ & sewage tank & $24 / 07 / 2010$ \\
Beijing & Beijing $\left(39^{\circ} 54^{\prime} \mathrm{N}, 116^{\circ} 28^{\prime} \mathrm{E}\right)$ & BJI & $29 / 07 / 2010$ \\
Liaoning & Pulandian $\left(39^{\circ} 23^{\prime} \mathrm{N}, 121^{\circ} 58^{\prime} \mathrm{E}\right)$ & LPU & $20 / 07 / 2010 \quad$ sewage \\
\hline
\end{tabular}


combined for correlation analysis between resistance levels of insecticides (dichlorvos, parathion, chlorpyrifos, propoxur and BPMC) and Ester phenotype frequencies and among phenotype frequencies of various Ester alleles using SPSS 13.0.

\section{Results}

\section{Insecticide resistance status of field populations}

Five field populations of C. p. pallens, collected in north China (Table 1), were tested for resistance levels towards frequently applied organophosphate, pyrethroid, and carbamate insecticides with larvae bioassays. The tests were finished within three generations (F1-F3) after the mosquitoes were brought back and raised in the lab. Bioassay results indicate that the five populations showed highest resistance levels towards pyrethroids, followed by organophosphates, and last to carbamates (Table 2). For the two pyrethroid insecticides, resistance to permethrin was higher than to deltamethrin. Most of the populations had a resistance ratio (RR) higher than 10 to permethrin, with the highest reaching 68 folds in the population TAA, while lower than 10 to deltamethrin. For the three organophosphate insecticides, several populations showed medium resistance (RR between 10 and 20) to dichlorvos, while for fenitrothion and malathion only lower than 4-fold resistance was observed. All the populations had low resistance (RR lower than 10) to the two carbamate insecticides, propoxur and BPMC.

Populations from Henan (WHE and YUY) and Shandong (TAA) provinces were more resistant to insecticides than those from Beijing (BJI) and Liaoning (LPU) province. BJI and LPU showed low levels of resistance to all tested insecticides. Populations WHE, YUY, and TAA had medium resistance to dichlorvos, and high resistance (RR higher than 20) to permethrin.

\section{Identification of esterase phenotypes}

In order to detect the types of high active carboxylesterases, at least thirty individual adult mosquitoes of each population were applied to starch gel electrophoresis. It has been reported that these high active carboxylesterases are expressed in both adults and larvae [22,23]. A total of 200 adult mosquitoes were checked for the five populations (Table 3). Six types of overproduced esterases were identified in this investigation, i.e. B1, A2-B2, A8-B8, A9-B9, B10, and A11-B11. In the populations from Henan province (WHE and YUY), all six types of esterases were detected, and four esterases co-existed in one population, WHE. In the other three populations, only B1 and A2-B2 were detected (Figure 1). B1 was the predominant esterase, with frequencies over $70 \%$ in most populations. Although the frequencies of A2-B2 were not as high as B1, it still had a distribution as broad as B1. Esterases A8-B8, A9-B9, $\mathrm{B} 10$ and A11-B11 were minor, with limited distribution and low frequencies.

\section{Correlation analysis}

Correlation analyses between insecticide resistance levels (dichlorvos, parathion, chlorpyrifos, propoxur and $\mathrm{BPMC}$ ) and Ester phenotype frequencies showed that the frequencies of esterases A8-B8 and A9-B9 positively correlated to the resistance levels of dichlorvos, parathion, chlorpyrifos and propoxur. Esterase B10 only positively correlated to dichlorvos resistance, even though the correlation coefficients $\left(\mathrm{R}^{2}\right)$ were not high (Figure 2). None of the six types of esterases displayed a linear correlation to the BPMC resistance in mosquitoes. Frequencies of esterases B1, A2-B2, and A11-B11 did not linearly correlate to any resistance of the five insecticides. For each insecticide, except for BPMC, multiple types of esterases had a positive relationship with its resistance in mosquitoes.

The correlation among phenotype frequencies of various Ester alleles was also checked. The results demonstrate that there were positive correlations between phenotype frequencies of A8-B8 and A9-B9, A8-B8 and $\mathrm{B} 10, \mathrm{~A} 9-\mathrm{B} 9$ and $\mathrm{B} 10$, and a negative correlation between $\mathrm{A} 8-\mathrm{B} 8$ and B1 (Figure 3). The existence of A2-B2 or A11-B11 had no linear relationship with other esterases.

\section{Discussion}

As a periodic investigation, we surveyed the resistance levels of five field populations of C. p. pallens towards seven insecticides commonly used in mosquito control in China. High and medium resistance appeared to pyrethroids and organophosphates, in some populations, respectively, and only low resistance was observed for carbamates in the five populations. Compared with previous investigations in 2003 [12] and 2006 [13], there is no remarkable change in the organophosphate and carbamate resistance status in the 2010 survey. The resistance to dichlorvos is still leading in organophosphate resistance. Low resistance to the two carbamate insecticides implies that there is still no target resistance mediated by G119S mutation in the acetylcholinesterase 1. On the other hand, the pyrethroid resistance seems elevated, especially the resistance to permethrin. Most of the populations in this survey had the permethrin resistance ratio higher than 10, including the Beijing population BJI, while the other four Beijing populations surveyed in 2006 were susceptible or only showed resistance below 2 fold towards permethrin and tetramethrin [13]. This is the aftermath of an increase of pyrethroid insecticides applied in recent years in China.

In this study we observed six highly active carboxylesterases in these northern populations. The overall 
Table 2 Resistance observed in bioassays to seven insecticides in five populations of Culex pipiens pallens from China.

\begin{tabular}{|c|c|c|c|c|c|c|c|}
\hline Insecticides & Populations & $\mathrm{N}$ & LC50 (95\% Cl) (mg/L) & Slope (SE) & $\chi^{2}$ & RR $(95 \% \mathrm{Cl})$ & G \\
\hline \multirow[t]{6}{*}{ Dichlorvos } & S-LAB & 300 & $0.19(0.18-0.19)$ & $13.8(1.6)$ & 1.7 & 1 & F2 \\
\hline & WHE & 240 & $3.04(2.86-3.17)$ & $8.0(1.3)$ & 4.8 & $16.4(12.3-21.7)$ & $\mathrm{F} 1$ \\
\hline & YUY & 240 & $3.86(3.22-4.07)$ & $11.1(3.4)$ & 0.5 & $20.8(13.4-32.3)$ & $\mathrm{F} 1$ \\
\hline & TAA & 300 & $2.91(2.11-3.27)$ & $5.2(1.4)$ & 0.4 & $15.7(10.2-24.3)$ & F2 \\
\hline & BJI & 300 & $1.26(1.19-1.33)$ & $9.7(1.3)$ & 1.6 & $6.8(4.9-9.4)$ & F2 \\
\hline & LPU & 300 & $1.06(0.88-1.14)$ & $7.4(2.3)$ & 1.6 & $5.7(3.9-8.3)$ & F2 \\
\hline \multirow[t]{6}{*}{ Fenitrothion } & $S-L A B$ & 300 & $0.0078(0.0076-0.0081)$ & $15.8(1.8)$ & 5.2 & 1 & F2 \\
\hline & WHE & 300 & $0.015(0.014-0.016)$ & $6.8(1.6)$ & 2.3 & $1.9(1.4-2.6)$ & $\mathrm{F} 1$ \\
\hline & YUY & 360 & $0.0099(0.0084-0.011)$ & $4.0(0.9)$ & 0.4 & $1.3(0.9-1.7)$ & $\mathrm{F} 1$ \\
\hline & TAA & 240 & $0.020(0.018-0.022)$ & $6.6(1.7)$ & 1.5 & $2.5(1.8-3.6)$ & $\mathrm{F} 1$ \\
\hline & BJI & 300 & $0.0096(0.0088-0.010)$ & $5.6(0.7)$ & 0.8 & $1.2(0.9-1.6)$ & F2 \\
\hline & LPU & 300 & $0.015(0.014-0.016)$ & $6.9(1.0)$ & 0.6 & $1.9(1.4-2.6)$ & F2 \\
\hline \multirow[t]{6}{*}{ Malathion } & S-LAB & 240 & $0.025(0.020-0.030)$ & $12.0(4.1)$ & 7.3 & 1 & F2 \\
\hline & WHE & 360 & $0.094(0.089-0.099)$ & $7.4(0.8)$ & 2.2 & $3.8(1.8-8.0)$ & F2 \\
\hline & YUY & 360 & $0.073(0.069-0.076)$ & $6.8(1.6)$ & 2.3 & $3.0(1.4-6.2)$ & $\mathrm{F} 1$ \\
\hline & TAA & 300 & $0.080(0.073-0.086)$ & $6.9(1.5)$ & 3.0 & $3.3(1.4-7.8)$ & $\mathrm{F} 1$ \\
\hline & BJ & 300 & $0.073(0.066-0.081)$ & $4.1(0.6)$ & 3.9 & $3.0(1.4-6.3)$ & F2 \\
\hline & LPU & 240 & $0.052(0.044-0.062)$ & $3.7(0.6)$ & 1.4 & $2.1(0.9-5.2)$ & $\mathrm{F} 2$ \\
\hline \multirow[t]{6}{*}{ Deltamethrin } & S-LAB & 300 & $0.00039(0.00036-0.00043)$ & $5.3(1.1)$ & 0.3 & 1 & F2 \\
\hline & WHE & 360 & $0.0026(0.0021-0.0029)$ & $4.1(0.9)$ & 6.0 & $6.6(4.9-8.7)$ & F2 \\
\hline & YUY & 360 & $0.0046(0.0022-0.0054)$ & $3.8(1.3)$ & 0.05 & $11.7(7.4-18.1)$ & $\mathrm{F} 1$ \\
\hline & TAA & 240 & $0.0039(0.0029-0.0046)$ & $2.3(0.5)$ & 0.4 & $9.9(7.4-12.9)$ & F2 \\
\hline & BJ & 300 & $0.0023(0.0020-0.0024)$ & $5.8(1.4)$ & 0.004 & $5.8(4.3-7.6)$ & F2 \\
\hline & LPU & 240 & $0.0014(0.0007-0.0017)$ & $3.8(1.1)$ & 0.01 & $3.5(2.1-5.9)$ & F2 \\
\hline \multirow[t]{6}{*}{ Permethrin } & S-LAB & 300 & $0.0017(0.0016-0.0019)$ & $5.6(0.6)$ & 4.8 & 1 & F2 \\
\hline & WHE & 300 & $0.038(0.035-0.041)$ & $9.4(1.8)$ & 0.4 & $21.9(15.6-30.5)$ & F2 \\
\hline & YUY & 300 & $0.055(0.043-0.062)$ & $3.8(0.9)$ & 2.1 & $31.9(22.9-43.9)$ & $\mathrm{F} 1$ \\
\hline & TAA & 300 & $0.12(0.04-0.17)$ & $1.4(0.4)$ & 0.2 & $68.2(46.9-99.0)$ & F2 \\
\hline & BJ & 360 & $0.024(0.023-0.025)$ & $11.0(1.8)$ & 2.0 & $13.8(10.3-18.5)$ & F2 \\
\hline & LPU & 240 & $0.016(0.011-0.021)$ & $2.0(0.6)$ & 0.4 & $9.5(6.9-12.9)$ & F3 \\
\hline \multirow[t]{6}{*}{ Propoxur } & S-LAB & 300 & $0.13(0.13-0.14)$ & $9.7(1.4)$ & 0.6 & 1 & F2 \\
\hline & WHE & 300 & $0.28(0.26-0.31)$ & $7.1(1.6)$ & 1.2 & $2.1(1.5-2.9)$ & F2 \\
\hline & YUY & 300 & $0.18(0.09-0.21)$ & $4.9(1.6)$ & 1.6 & $1.3(0.8-2.3)$ & $\mathrm{F} 1$ \\
\hline & TAA & 300 & $0.27(0.25-0.28)$ & $9.7(1.4)$ & 0.2 & $2.0(1.5-2.7)$ & F2 \\
\hline & BJI & 300 & $0.23(0.21-0.25)$ & $8.5(2.1)$ & 0.1 & $1.8(1.3-2.5)$ & F2 \\
\hline & LPU & 300 & $0.21(0.19-0.23)$ & $6.5(2.0)$ & 0.3 & $1.6(1.2-2.1)$ & F2 \\
\hline \multirow[t]{6}{*}{ BPMC } & S-LAB & 300 & $0.097(0.025-0.35)$ & $10.8(3.8)$ & 6.2 & 1 & F2 \\
\hline & WHE & 360 & $0.39(0.36-0.42)$ & $7.7(2.1)$ & 3.5 & $4.0(0.9-17.7)$ & F2 \\
\hline & YUY & 240 & $0.23(0.17-0.26)$ & $3.5(0.7)$ & 4.5 & $2.3(0.8-7.2)$ & $\mathrm{F} 1$ \\
\hline & TAA & 240 & $0.42(0.39-0.44)$ & $12.7(2.6)$ & 0.2 & $4.3(1.0-19.2)$ & F2 \\
\hline & BJ & 300 & $0.34(0.31-0.35)$ & $8.9(1.4)$ & 0.4 & $3.4(1.2-10.2)$ & F2 \\
\hline & LPU & 300 & $0.21(0.16-0.24)$ & $3.9(1.0)$ & 0.2 & $2.1(0.5-9.6)$ & F3 \\
\hline
\end{tabular}

$S-L A B$, the susceptible reference strain. $N$, number of larvae tested. $C l$, confidence interval. $R R$, resistance ratio $\left(L C_{50}\right.$ of the population/LC 50 of $\left.S-L A B\right)$. $G$, the generation considered in bioassays.

pattern of their frequencies in geographic distribution is consistent with the reports seven years prior to this study [5,12]. Henan province still has impressive diversity of Ester alleles. Shandong and Liaoning provinces also only have Ester ${ }^{B 1}$ and Ester ${ }^{2}$. This means the Ester alleles did not extend their geographic range during the seven years in these areas. In the Beijing population, where four Ester alleles were recorded previously, only $E_{\text {ster }}{ }^{B 1}$ and Ester ${ }^{2}$ were observed. One possible reason for this difference could be that our sample size in the Beijing region was not large enough. More attention should be given to this region in future. 
Table 3 Frequency* of mosquitoes displaying a given overproduced esterase in field populations of Culex pipiens pallens in China

\begin{tabular}{lllllllll}
\hline $\begin{array}{l}\text { Population } \\
\text { code }\end{array}$ & N & B1 & $\begin{array}{l}\text { A2- } \\
\text { B2 }\end{array}$ & $\begin{array}{l}\text { A8- } \\
\text { B8 }\end{array}$ & $\begin{array}{l}\text { A9- } \\
\text { B9 }\end{array}$ & $\begin{array}{l}\text { B10 } \\
\text { A11- } \\
\text { B11 }\end{array}$ & SS \\
\hline WHE & 35 & 0.83 & 0 & 0 & 0.09 & 0.06 & 0.03 & 0.06 \\
YUY & 41 & 0.88 & 0.2 & 0.05 & 0 & 0 & 0 & 0.17 \\
TAA & 45 & 0.98 & 0.04 & 0 & 0 & 0 & 0 & 0.02 \\
BJI & 36 & 0.72 & 0.03 & 0 & 0 & 0 & 0 & 0.25 \\
LPU & 43 & 0.56 & 0.14 & 0 & 0 & 0 & 0 & 0.33 \\
\hline
\end{tabular}

* The sum of phenotypic frequency in each population is not necessarily equal to 1, considering some individuals are heterozygous with two overproduced esterases.

$\mathrm{N}$, the sample size analyzed. SS, the non-overproduced esterase phenotype.
Among the six types of Ester alleles, Ester ${ }^{8}$ and Ester ${ }^{9}$ have linear correlation with resistance to four organophosphate or carbamate insecticides and Ester ${ }^{B 10}$ to one organophosphate insecticide in field populations. These three alleles are adaptive to the selection pressure endemic to China, and the occurrences of these alleles are positively correlated at a certain coefficient. In contrast, two ubiquitously distributed alleles around the world, $E_{\text {ster }}{ }^{B 1}$ and Ester ${ }^{2}$, do not show linear correlation with resistance to any one of the five insecticides, implying that they play a general role in organophosphate and carbamate resistance. Although the endemic allele Ester $^{11}$ did not linearly correlate with resistance to the five insecticides, this can not rule out the possible

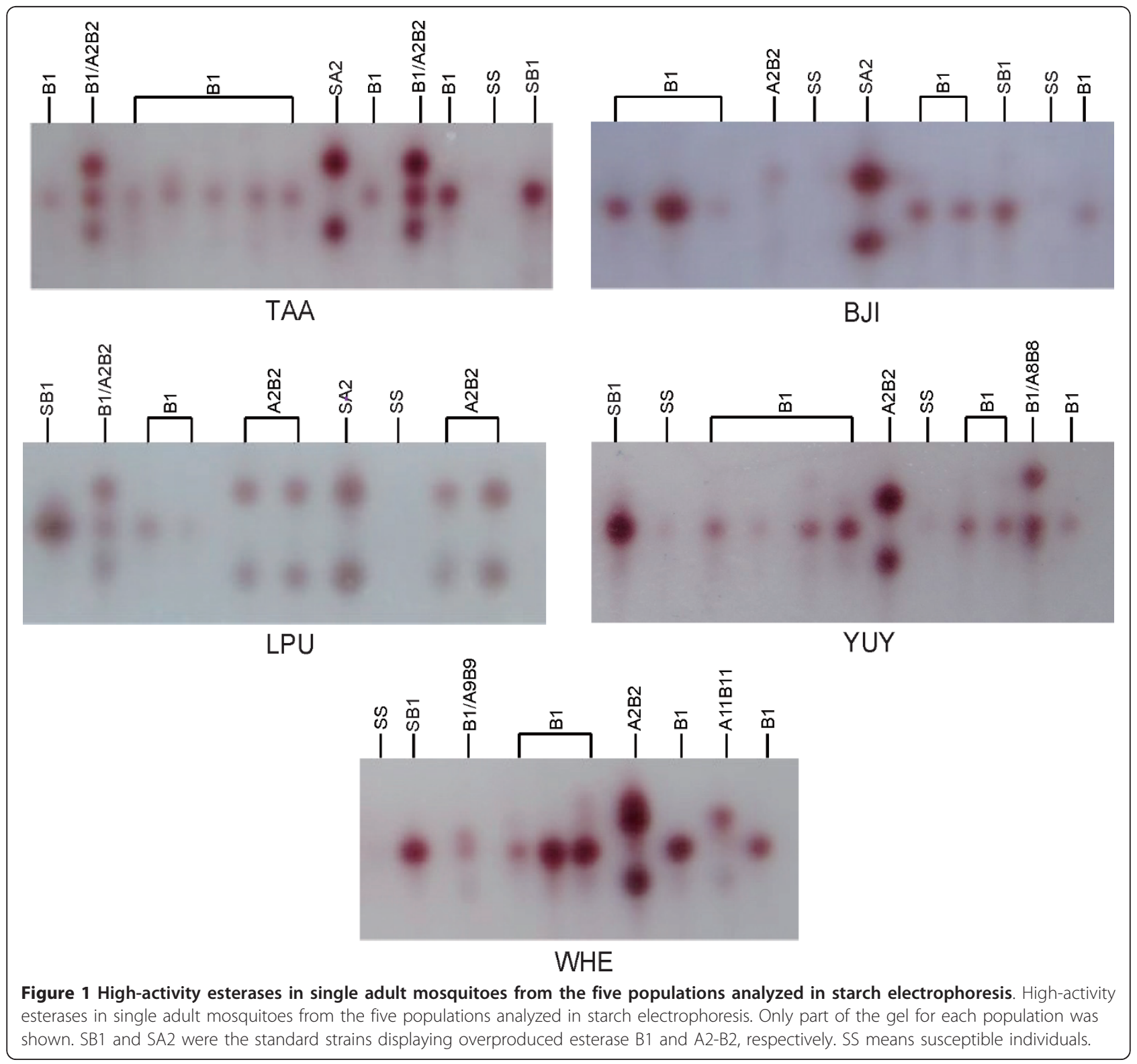




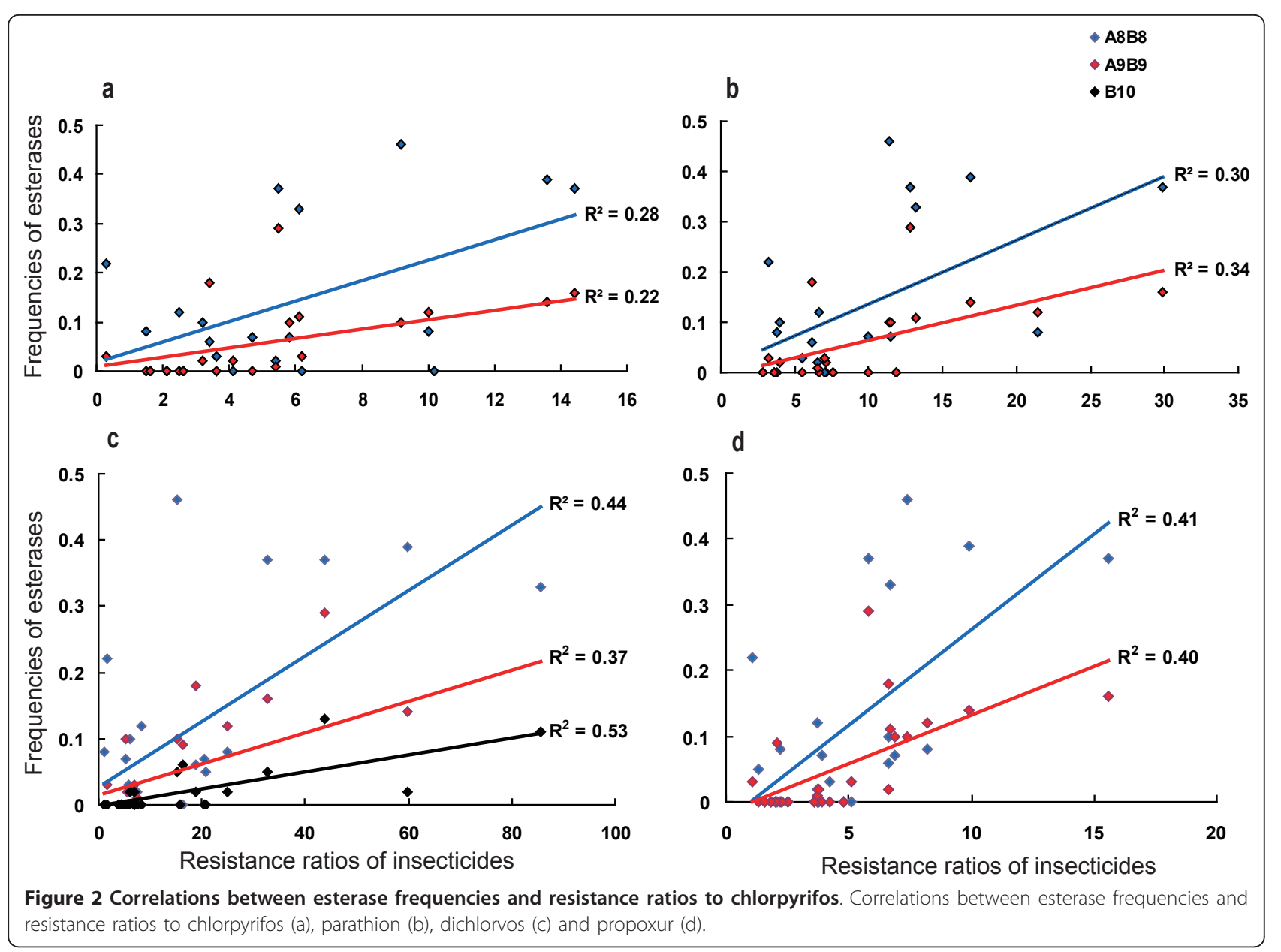

correlation of Ester ${ }^{11}$ with resistance to malathion, fenitrothion, or other insecticides used in China.

Our results suggest that one insecticide can select multiple Ester alleles and one Ester allele can work on multiple insecticides. So the evolutionary scenario of carboxylesterases under insecticide selection in the field is most likely "one to many", not "one to one". The relationship of Ester ${ }^{B 1}$ and $E s t e r^{8}$ is very interesting. Their

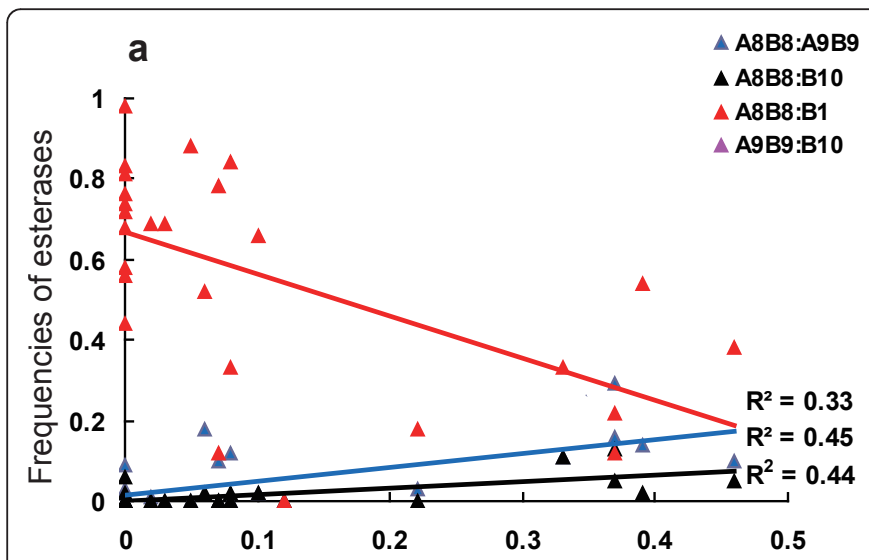

Frequencies of esterases

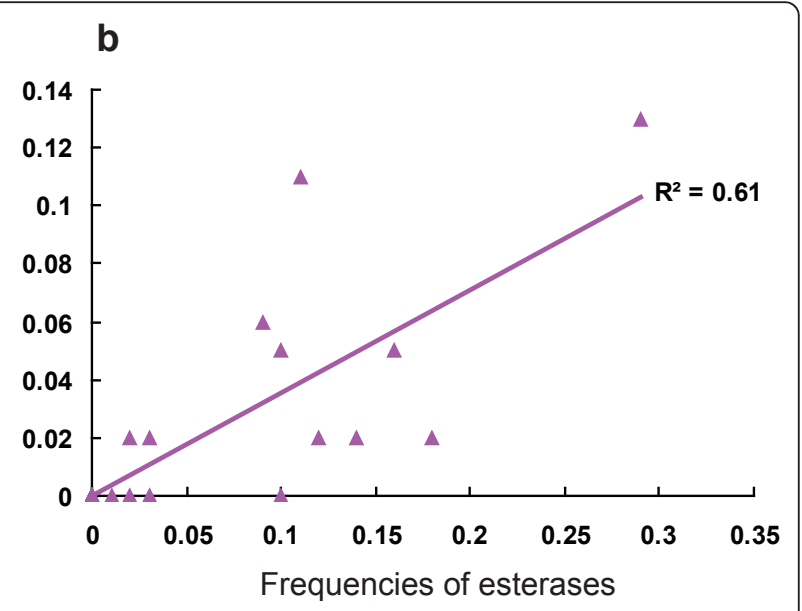

Figure 3 Correlations among frequencies of various esterases. Correlations among frequencies of various esterases. (a) between A8-B8 and A9-B9, A8-B8 and B10, and A8-B8 and B1; (b) between A9-B9 and B10. 
occurrence seems to contradict each other. This allelic competition was illustrated by the situation in southern France, where Ester ${ }^{1}$ had been replaced by Ester ${ }^{4}$ over a 10 year period [24], and then followed by the local occurrence of Ester ${ }^{2}$ [25]. It is likely that, in the future, as the result of the allelic competition, Ester ${ }^{B 1}$ will be eliminated from regions predominated by $E s t e r^{8}$, such as the Guangdong province, and Ester ${ }^{8}$ will be prevented from invading, or eliminated from, regions predominated by $E_{s t e r}{ }^{B 1}$ such as Beijing, and the Shandong province. Future work is needed to identify the parameters driving the competition between these two alleles.

\section{Conclusion}

Our analysis suggests that one insecticide can select multiple Ester alleles and one Ester allele can work on multiple insecticides. The evolutionary scenario of carboxylesterases under insecticide selection is possibly "one to many". This study will shed light on the understanding of the evolution of insecticide resistance genes in field populations and guide the management of insecticide resistance.

\section{Acknowledgements}

We are very grateful to Montana Atwater for providing constructive comments on the manuscript. This work is supported by the grant from the Major State Basic Research Development Program of China (973 Program) (No. 2012CB114102) and the Important National Science \& Technology Specific Project (No. 2012ZX10004219-003).

\section{Author details}

'Plant Protection College, Shandong Agricultural University, Tai'an, Shandong, 271018 China. ${ }^{2}$ State Key Laboratory of Integrated Management of Pest Insects \& Rodents, Institute of Zoology, Chinese Academy of Sciences, Beijing, 100101 China.

\section{Authors' contributions}

$Y L$ and $H Z$ performed the study, analyzed the data and drafted the manuscript. CQ supervised the study and helped draft the manuscript. XL and FC conceived and designed the study, and helped draft the manuscript. All authors approved the final version of the manuscript.

\section{Competing interests}

The authors declare that they have no competing interests.

Received: 17 October 2011 Accepted: 19 December 2011 Published: 19 December 2011

\section{References}

1. Hemingway J, Ranson $\mathrm{H}$ : Insecticide resistance in insect vectors of human disease. Annu Rev Entomol 2000, 45:371-391.

2. Liu N, Xu Q, Zhu F, Zhang L: Pyrethroid resistance in mosquitoes. Insect Sci 2006, 13:159-166

3. Kamgang B, Marcombe S, Chandre F, Nchoutpouen E, Nwane P, Etang J, Corbel V, Paupy C: Insecticide susceptibility of Aedes aegypti and Aedes albopictus in Central Africa. Parasit Vectors 2011, 4:79.

4. Lima EP, Paiva MH, de Araújo AP, da Silva EV, da Silva UM, de Oliveira LN, Santana AE, Barbosa CN, de Paiva Neto CC, Goulart MO, Wilding CS, Ayres CF, de Melo Santos MA: Insecticide resistance in Aedes aegypti populations from Ceará, Brazil. Parasit Vectors 2011, 4:5.

5. Cui F, Tan Y, Qiao CL: Filariasis vector in China: Insecticide resistance and population structure of mosquito Culex pipiens complex. Pest Manag Sci 2007, 63:453-458.
6. Hemingway J, Hawkes NJ, McCarroll L, Ranson H: The molecular basis of insecticide resistance in mosquitoes. Insect Biochem Mol Biol 2004, 34:653-665.

7. Kadous AA, Ghiasuddin SM, Matsumura F, Scott JG, Tanaka K: Difference in the picrotoxinin receptor between the cyclodiene-resistant and susceptible strains of the German cockroach. Pestic Biochem Physiol 1983, 19:157-166.

8. Rooker S, Guillemaud T, Berge J, Pasteur N, Raymond M: Coamplification of esterase $\mathrm{A}$ and $\mathrm{B}$ genes as a single unit in Culex pipiens mosquitoes. Heredity 1996, 77:555-561.

9. Raymond M, Chevillon C, Guillemaud T, Lenormand T, Pasteur N: An overview of the evolution of overproduced esterases in the mosquito Culex pipiens. Philos Trans R Soc Lond B Biol Sci 1998, 353:1707-1711.

10. Raymond M, Berticat C, Weill M, Pasteur N, Chevillon C: Insecticide resistance in the mosquito Culex pipiens: what have we learned about adaptation? Genetica 2001, 112-113:287-296.

11. Cheikh RB, Berticat C, Berthomieu A, Pasteur N, Cheikh HB, Weill M: Characterization of a novel high-activity esterase in Tunisian populations of the mosquito Culex pipiens. J Econ Entomol 2008, 101:484-491.

12. Cui F, Lin LF, Qiao CL, Xu Y, Marquine M, Weill M, Raymond M: Insecticide resistance in Chinese populations of the Culex pipiens complex through esterase overproduction. Entomol Exp Appl 2006, 120:211-220.

13. Yan S, Wu Z, Cui F, Zhao Q, Qiao C: Dynamics of esterase alleles in Culex pipiens complex mosquitoes in Beijing. J Econ Entomol 2008, 101:1897-1902

14. Georghiou GP, Metcalf RL, Gidden FE: Carbamate-resistance in mosquitoes: Selection of Culex pipiens fatigans Wiedemann. (= C. quinquefasciatus Say) for resistance to Baygon. Bull World Health Organ 1966, 35:691-708.

15. Berticat C, Rousset F, Raymond M, Berthomieu A, Weill M: High Wolbachia density in insecticide-resistant mosquitoes. Proc Biol Sci 2002, 269:1413-1416.

16. Weill M, Marquine M, Berthomieu A, Dubois MP, Bernard C, Qiao CL, Raymond M: Identification and characterization of novel organophosphate detoxifying esterase alleles in the Guangzhou area of China. J Am Mosa Control Assoc 2001, 17:238-244.

17. Raymond M, Marquine M: Evolution of insecticide resistance in Culex pipiens populations: The Corsican paradox. J Evol Biol 1994, 7:315-337.

18. Finney DJ: Probit Analysis Cambridge: Cambridge University Press; 1971.

19. Raymond M: PROBIT CNRS-UMII. Licence L93019, Avenix, 24680 St. Georges d'Orques, France 1993.

20. Pasteur N, Iseki A, Georghiou GP: Genetic and biochemical studies of the highly active esterases $A^{\prime}$ and $B$ associated with organophosphate resistance in mosquitoes of the Culex pipiens complex. Biochem Genet 1981, 19:909-919.

21. Pasteur N, Pasteur G, Bonhomme F, Britton-Davidian J: Practical Isozyme Genetics Chichester: Ellis Horwood Press; 1988

22. Callaghan A, Boiroux V, Raymond M, Pasteur N: Prevention of changes in the electrophoretic mobility of overproduced esterases from organophosphate-resistant mosquitoes of the Culex pipiens complex. Med Vet Entomol 1994, 8:391-394.

23. Pasteur N, Nancé E, Bons N: Tissue Localization of Overproduced Esterases in the mosquito Culex pipiens (Diptera: Culicidae). J Med Entomol 2001, 38:791-801.

24. Guillemaud T, Lenormand T, Bourguet D, Chevillon C, Pasteur N, Raymond M: Evolution of resistance in Culex pipiens: allele replacement and changing environment. Evolution 1998, 52:443-453.

25. Labbé $P$, Lenormand $T$, Raymond $M$ : On the worldwide spread of one insecticide resistance gene: historical chance, genetic drift or competitive advantage. J Evol Biol 2005, 18:1471-1484

doi:10.1186/1756-3305-4-236

Cite this article as: Liu et al:: Correlation between carboxylesterase alleles and insecticide resistance in Culex pipiens complex from China. Parasites \& Vectors 2011 4:236. 